\title{
IMPLEMENTING A CUSTOMISED SOFTWARE FOR WEIGHT MANAGEMENT OF OVERWEIGHT AND OBESE PEOPLE
}

\author{
V. Panayotov, K. Petkov, N. Iankova, J. Karabiberov
}

SUMMARY

Introduction: The rate of obesity escalated in many countries in recent years. A lot of different methodologies have been implemented to address this problem. A relatively new approach is using weight management computer software. Methods: Our aim was to evaluate the impact of software driven process of calorie counting and exercise tracking on weight changes in overweight and obese people. We compared the results to those of applying a conventional approach for losing weight - following the instructions of a dietitian and a fitness instructor. 60 participants were randomly assigned to 3 groups - two experimental and one control. The experimental groups underwent an energy deficient diet plan and exercised for about $90 \mathrm{~min}$. a week. No dietary restrictions were imposed on the subjects in the control group. The study was 24 weeks long.

Results. We compared the differences in body mass and fat tissue percentage within and between the groups. We found significant differences between the initial and the final values of these variables in both experimental groups (bigger ones in the first group).

No significant differences were found for the subjects in the control group.

Discussion: All experimental participants, who successfully finished the experiment, reduced their weight and body fat. Conclusions: There is preliminary evidence for a superiority of the implemented software in the process of weight reduction for overweight and obese people. Further studies are necessary for reaching more convincing results.

Key words: overweight, obese, weight management, software, exercise

\section{Introduction}

According to a study of the National Centre of Social Health in $2010-201130 \%$ of Bulgarian students aged between 6 and 19 were overweight and $12 \%$ were obese. The data for the countries in the Eurozone were even more alarming: between $36.9 \%$ and $56.7 \%$ of women and between $51 \%$ and $69.3 \%$ of men were overweight and obese (http://epp. eurostat.ec.europa.eu/statistics explained/index. php/Overweight and obesity - BMI statistics, 2015). Obese young people are at extremely high risk of morbidity with high social impact such as type 2 diabetes and cardiovascular disease (Maehlum S, et al., 1986, Rexrode KM, et al., 1997). At the same time there is no complex methodology available, which to combine the two most effective approaches for treating obesity - healthy diet and physical activity.

There are a number of studies on similar topics (Brill JB, et al., 2002, Borsheim E, Bahr R., 2003, Brzycki, M., 1998, De Feo P, et al., 2003, Demling RH, DeSanti L. 2000, Doi T, et al., 2001, Earle RW, Wathen D, 2000, Meckling KA, et al., 2002, Meckling KA, et al., 2002, Poehlman ET, Horton ES, 1989, Pisunyer FX., 1993, Racette SB, et al., 1995, Sykes K, Choo LL, Cotterrell M., 2004, Tsai AC, et al., 2003, Walberg JL., 1989, Wilmore JH, et al., 1999). Despite the fact that there are studies focused on researching daily regimens, which combine resistance exercises and negative energy balances, we did not find one in the literature to test the effectiveness of a methodology similar to ours. In our opinion, combining a daily schedule consisting of anaerobic training and a low-caloric diet under software supervision is an entirely new approach for treating obesity.

\section{Aim and objectives of the study}

the aim of the study was to evaluate the impact of software driven process of calorie counting and exercise tracking of the weight and body composition changes in overweight and obese people.

\section{Objectives:}

1. To recruit a group of sedentary subjects with BMI values of more than 27;

2. To split the subjects randomly into 3 groups- two experimental to follow low-caloric diets and one control with no energy consumption restrictions;

3. To estimate the theoretical daily energy expenditure of every participant every 2 weeks;

4. To upload the data of every participant of first experimental group into the diet software; 
5. To design a diet regimen for every subject in the experimental group No.2;

6. To put the experimental subjects to a regimen of physical activity for 24 weeks;

7. To measure and evaluate statistically the differences between the initial and the final values of the variables we studied within and between the groups.

\section{Methods}

We studied 60 sedentary subjects of both genders, aged between 25 and 45 with BMI>27. We did not control for gender differences in the studied variables. We estimated the theoretical daily energy expenditure for every participant: we used the Mifflin et al. (Mifflin, MD, et al., 1990) methodology to estimate the theoretical energy expenditure at rest and after that we applied the Levine and Kotz (Levine, J. A. and Kotz, C. M., 2005) methodology to calculate the theoretical overall daily energy expenditure.

49 out of 60 subjects completed the experiment successfully.

We split the participants randomly into 3 groups. The first two groups were put on a 30\% calorie deficient diet (comparing to the theoretically estimated daily energy expenditure) with the following proportions of food ingredients: $55-60 \%$ of carbohydrates, $15-20 \%$ of protein and $25-30 \%$ of fats. We controlled for the pursuance of the regimen via a feedback mechanism - the participants of experimental group No. 1 uploaded their daily consumptions in the software; every participant in the experimental group No.2 had to complete protocols for the food consumed on a daily basis. The third group we used as a control one - no restrictions upon food intake and physical activity were imposed on the subjects.

Every two weeks we measured the body mass and the quantity of adipose tissue (as a percentage of body mass) of every subject using the bioimpedance methodology (Kyle UG, et al., 2004) and updated the theoretical energy expenditure accordingly.

The energy deficiency was achieved via reduction of the calorie intake using conventional food sources. No food supplements were allowed.
The physical activity program consisted of training sessions with different parameters depending on each subject's preferences. The only mandatory demands were for it to be of a predominantly anaerobic type and of metabolic equivalent of task (MET) (Jette, M. et al., 1990, Zatsiorski, V., 1990) between 600 and 1680 units weekly. The unification of the energetic costs of the exercise allowed us to compare statistically correctly the impacts of physical activities of different types (not cited here).

\section{Results}

The variation analysis is presented on table 1 . To check for differences between the groups for each variable we conducted a standard test for differences in mean values - ANOVA (table 2) (Rutherford, A., 2011). This procedure was necessary for the verification of a successful initial randomization of the participants. Our data was consistent with the assumptions of the test (data not presented). Based on the results we concluded that there are no differences between the initial mean values of the studied variables between the groups $(p \leq 0.05)$. ANOVA on final values was aimed at checking for differences in studied variables both between and within the groups. To account for the possibility of type I error during the post-hoc analysis, we applied a Bonferroni corrected procedure of ANOVA (http://www. winsteps.com/winman/bonferroni.htm). Results are represented on table 2.

To evaluate quantitatively the impact of the program we applied t-tests for paired samples for the participants of each group (James, G. et al, 2013). The results are presented on tables 3 and 4 .

Table 1 Variation analysis

\begin{tabular}{|l|l|l|l|l|l|l|l|}
\hline & N & Range & Min & Max & Mean & $\begin{array}{l}\text { Std. De- } \\
\text { viation }\end{array}$ & Var \\
\hline BMb1 & 16 & 40.10 & 75.80 & 116.00 & 93.83 & 11.24 & 126.32 \\
\hline BMe1 & 16 & 59.70 & 54.60 & 114.30 & 83.16 & 14.21 & 201.94 \\
\hline FTb1 & 16 & 13.20 & 30.80 & 44.00 & 38.61 & 3.23 & 10.46 \\
\hline FTe1 & 16 & 15.00 & 24.50 & 39.50 & 32.64 & 3.65 & 13.38 \\
\hline BMb2 & 15 & 51.30 & 77.60 & 128.90 & 101.23 & 12.98 & 168.65 \\
\hline BMe2 & 15 & 50.30 & 62.50 & 112.80 & 88.79 & 14.14 & 200.13 \\
\hline FTb2 & 15 & 14.80 & 29.00 & 43.80 & 36.21 & 4.58 & 21.01 \\
\hline FTe2 & 15 & 16.00 & 25.00 & 41.00 & 32.47 & 4.58 & 21.06 \\
\hline BMbC & 18 & 44.80 & 81.20 & 126.00 & 99.44 & 11.62 & 135.07 \\
\hline BMeC & 18 & 43.00 & 82.00 & 125.00 & 99.64 & 11.34 & 128.74 \\
\hline FTbC & 18 & 17.20 & 27.20 & 44.40 & 36.71 & 4.02 & 16.21 \\
\hline FTeC & 18 & 17.00 & 27.50 & 44.50 & 36.63 & 4.10 & 16.89 \\
\hline
\end{tabular}

Legend: BMb1 -initial body mass of experimental group 1; BMe1 - final body mass of experimental group 1; BMb2 - initial body mass of experimental group 2; BMe2 - 
final body mass of experimental group 2; BMbC - initial body mass of the control group; $\mathrm{BMeC}$ - final body mass of the control group; FTb1-initial percentage of adipose tissue of experimental group 1; FTe1 - final percentage of adipose tissue of experimental group 1; FTb2 - initial percentage of adipose tissue of experimental group 1; FTe2 - final percentage of adipose tissue of experimental group 2; FTbC - initial percentage of adipose tissue of the control group; FTeC - final percentage of adipose tissue of the control group.

\section{Discussion}

No significant differences were found between the initial and the final values of the variables for the control group. The differences of both experimental groups were significant for the studied variables. The mean difference in $\mathrm{BM}$ was smaller in the first experimental group ( $10.66 \mathrm{~kg}$ vs. $12.61 \mathrm{~kg}$ ), which could be considered an evidence for superiority of human intervention compared to machine guidance.

Table 2 Bonferroni adjusted ANOVA

\begin{tabular}{|c|c|c|c|c|c|c|c|}
\hline \multirow{2}{*}{$\begin{array}{l}\text { Depen- } \\
\text { dent } \\
\text { Variable }\end{array}$} & \multirow{2}{*}{$\begin{array}{l}\text { (I) } \\
\text { group }\end{array}$} & \multirow{2}{*}{$\begin{array}{l}\text { (J) } \\
\text { group }\end{array}$} & \multirow{2}{*}{$\begin{array}{l}\text { MeanDif- } \\
\text { ference } \\
\text { (I-J) }\end{array}$} & \multirow{2}{*}{$\begin{array}{l}\text { Std. } \\
\text { Error }\end{array}$} & \multirow{2}{*}{ Sig. } & \multicolumn{2}{|c|}{$\begin{array}{l}\text { 95\% Confidence } \\
\text { Interval }\end{array}$} \\
\hline & & & & & & \begin{tabular}{|l|} 
Lower \\
Bound \\
\end{tabular} & $\begin{array}{l}\text { Upper } \\
\text { Bound } \\
\end{array}$ \\
\hline \multirow{4}{*}{$\mathrm{BMb}$} & \multirow{2}{*}{1.0} & 2.0 & -7.37 & 4.28 & .277 & -18.03 & 3.28 \\
\hline & & 3.0 & -5.61 & 4.10 & .533 & -15.80 & 4.57 \\
\hline & \multirow{2}{*}{2.0} & 1.0 & 7.37 & 4.28 & .277 & $\mid-3.28$ & 18.03 \\
\hline & & 3.0 & 1.76 & 4.17 & 1.000 & \begin{tabular}{|l|}
-8.60 \\
\end{tabular} & 12.13 \\
\hline \multirow{4}{*}{$\mathrm{BMe}$} & \multirow{2}{*}{1.0} & 2.0 & -5.62 & 4.74 & .725 & -17.42 & 6.16 \\
\hline & & 3.0 & $-16.47^{*}$ & 4.53 & .002 & -27.75 & -5.20 \\
\hline & \multirow{2}{*}{2.0} & 1.0 & \begin{tabular}{|l|l|}
5.62 \\
\end{tabular} & 4.74 & .725 & -6.16 & 17.42 \\
\hline & & 3.0 & -10.85 & 4.61 & .069 & -22.32 & .61 \\
\hline \multirow{4}{*}{ FTb } & \multirow{2}{*}{1.0} & 2.0 & 2.39 & 1.42 & .300 & -1.15 & 5.94 \\
\hline & & 3.0 & 1.90 & 1.36 & .512 & -1.49 & 5.29 \\
\hline & \multirow{2}{*}{2.0} & 1.0 & -2.39 & 1.42 & .300 & $\mid-5.94$ & 1.15 \\
\hline & & 3.0 & -.49 & 1.38 & 1.000 & \begin{tabular}{|l|}
-3.95 \\
\end{tabular} & 2.95 \\
\hline \multirow{4}{*}{$\mathrm{FTe}$} & \multirow{2}{*}{1.0} & 2.0 & .16 & 1.48 & 1.000 & -3.51 & 3.85 \\
\hline & & 3.0 & $-3.98^{\star}$ & 1.41 & .021 & \begin{tabular}{|l|}
-7.51 \\
\end{tabular} & -.46 \\
\hline & \multirow[b]{2}{*}{2.0} & 1.0 & -.16 & 1.48 & 1.000 & \begin{tabular}{|l|}
-3.85 \\
\end{tabular} & 3.51 \\
\hline & & 3.0 & $-4.15^{\star}$ & 1.44 & .018 & \begin{tabular}{|l|}
-7.74 \\
\end{tabular} &.- .57 \\
\hline
\end{tabular}

Table 3 Paired-samples t-tests

\begin{tabular}{|c|c|c|c|c|c|c|c|c|}
\hline \multirow{3}{*}{\multicolumn{2}{|c|}{ Mean }} & \multicolumn{5}{|c|}{ Paired Differences } & \multirow{3}{*}{$\mathrm{t}$} & \multirow{3}{*}{ df } \\
\hline & & \multirow{2}{*}{$\begin{array}{l}\text { Std. } \\
\text { Devi- } \\
\text { ation }\end{array}$} & \multirow{2}{*}{$\begin{array}{l}\text { Std. } \\
\text { Error } \\
\text { Mean }\end{array}$} & \multicolumn{2}{|c|}{$\begin{array}{l}95 \% \text { Confidence } \\
\text { Interval of the } \\
\text { Difference }\end{array}$} & & & \\
\hline & & & & Lower & Upper & & & \\
\hline Pair 1 & $\begin{array}{l}\text { BMb1 - } \\
\text { BMe1 }\end{array}$ & 10.66 & 5.27 & 1.31 & 7.85 & 13.48 & 8.083 & 15 \\
\hline Pair 2 & \begin{tabular}{|l|} 
FTb1 - \\
FTe1 \\
\end{tabular} & 5.97 & 3.03 & .75 & 4.35 & 7.58 & 7.880 & 15 \\
\hline Pair 3 & $\begin{array}{l}\text { BMb2 - } \\
\text { BMe2 }\end{array}$ & 12.41 & 4.63 & 1.19 & 9.84 & 14.98 & 10.376 & 14 \\
\hline Pair 4 & $\begin{array}{l}\text { FTb2 - } \\
\text { FTe2 }\end{array}$ & 3.74 & 1.96 & .50 & 2.65 & 4.83 & 7.389 & 14 \\
\hline Pair 5 & $\begin{array}{l}\text { BMbC - } \\
\text { BMeC } \\
\end{array}$ & -.19 & 1.66 & .39 & -1.02 & .62 & $\mid-.509$ & 17 \\
\hline Pair 6 & $\begin{array}{l}\text { FTbC - } \\
\text { FTeC }\end{array}$ & .08 & .34 & .08 & -.08 & .25 & 1.011 & 17 \\
\hline
\end{tabular}

Table 4 Linear correlation coefficients

\begin{tabular}{|l|l|l|l|l|}
\hline \multicolumn{2}{|l}{} & N & Correlation & Sig. \\
\hline Pair 1 & BMb1 \& BMe1 & 16 & .940 & .000 \\
\hline Pair 2 & FTb1 \& FTe1 & 16 & .619 & .011 \\
\hline Pair 3 & BMb2 \& BMe2 & 15 & .945 & .000 \\
\hline Pair 4 & FTb2 \& FTe2 & 15 & .909 & .000 \\
\hline
\end{tabular}

The mean difference in $\% \mathrm{FT}$ shows the opposite pattern (5.97 vs. $3.94 \mathrm{~kg}$ lost) - the software achieved a weight loss consisting predominantly of fats and spared the lean body mass. The post-hoc analysis of the data, on the other hand, does not confirm a hypothesis of a statistically significant superiority of the software over the conventional weight loss approach. This may be the result of the relatively small number of studied cases. In addition, the correlation coefficient between the initial and the final values of $\% \mathrm{FT}$ for the second experimental group is greater than that for the first one -0.619 vs. 0.909 . The correlation coefficient could be considered to some extent a measure of conservation of the distribution - the bigger the coefficient, the more similar the distributions. Using a very rough estimation, in this case, a participant with a high value of $\% \mathrm{FT}$ (compared to the mean) at the beginning of the study would most probably end up with a high\% - we would not witness a reshuffling of the distribution. This means that the bigger the correlation, the more consistent/targeted the methodology. We consider this finding as preliminary evidence for the superiority of conventional dieting approach over the software driven process. The body weight reduction under software assistance was achieved largely due to fat tissue loss and the same quantity of muscle tissue was spared, accordingly. The relative quantity of lean body mass increased and as it is well known, lean body mass consumes a lot more energy than fat tissue. More energy could be consumed without breaking the energy balance of the body (compared to the same body weight and the initial body composition). This is of great importance for obese people who, in most cases, have to maintain very restrictive diets (at least initially) to achieve a negative energy balance. It is very difficult to adhere to these types of diets for long periods of time. A preliminary interruption of the regimen is followed in most cases by switching to vastly positive energy balance and leads to a yo-yo effect, which swiftly increases the quantity of fat tissue of the body. This process is at the core of a vicious cir- 
cle - every consecutive round of such dieting failures brings in more fat tissue than at the beginning and lessens the relative quantity of muscle tissue.

\section{Conclusions}

Both approaches - software or dietitian assistance were successful in the process of long term weight loss;

A software guided weight loss process has the potential to successfully replace the conventional humanly led approach;

There are preliminary data for the superiority of a software-guided fat-loss process over the conventional methodology of human assistance;

Further studies are necessary for reaching to more definitive results concerning the effects of the studied software on body composition parameters.

\section{References}

Borsheim E, Bahr R. (2003) Effect of exercise intensity, duration and mode on post-exercise oxygen consumption. Sports Med; 33 (14): 1037-60

Brill JB, Perry AC, Parker L, et al. (2002) Dose-response effect of walking exercise on weight loss: how much is enough? Int J Obes; 26 (11): 1484-93

Brzycki, Matt (1998). A Practical Approach to Strength Training. McGraw-Hill Baechle TR

Cullinen K, Caldwell M. (1998) Weight training increases fat free mass and strength in untrained young women. J Am Diet Assoc; 98 (4): 414-8

De Feo P, Di Loreto C, Lucidi P, et al. (2003) Metabolic response to exercise. J Endocrinol Invest; 26 (9): 851-4

Demling RH, DeSanti L. (2000) Effect of a hypocaloric diet, increased protein intake and resistance training on lean mass gains and fat mass loss in overweight police officers. Ann Nutr Metab; 44 (1): 21-9

Doi T, Matsuo T, Sugawara M, et al. (2001) New approach for weight reduction by a combination of diet, light resistance exercise and the timing of ingesting a protein supplement. Asia Pac J Clin Nutr; 10 (3): 226-32 James, G. et al, (2013), An Introduction to Statistical Learning: with Applications in R (Springer Texts in Statistics), Springer, ISBN-13: 978-1461471370

Jette, M. et al. (1990), Metabolic Equivalents (METS) in Exercise Testing, Exercise Prescription, and Evaluation of Functional Capacity, Clin. Cardiol. 13, 555-565
Kyle UG, et al., (2004), Bioelectrical impedance analysis - part I: review of principles and methods, Clin Nutr, Oct;23(5):1226-43.

Levine, J. A. and Kotz, C. M. (2005). NEAT - non-exercise activity thermogenesis - egocentric and geocentric environmental factors vs. biological regulation. Acta Physiol. Scand. 184, 309-318.

Meckling KA, Gauthier M, Grubb R, et al. (2002) Effects of a hypo caloric, low-carbohydrate diet on weight loss, blood lipids blood pressure, glucose tolerance, and body composition, in free-living overweight women. Can J Physiol Pharmacol; 17 (5): 119-27

Mifflin, MD, et al. (1990), A new predictive equation for resting energy expenditure in healthy individuals., $\mathrm{Am} J$ Clin Nutr 51(2):241-7

Pisunyer FX. (1993) Medical hazards of obesity. Ann Intern Med; 119 (7): 655-60

Racette SB, Schoeller DA, Kushner RF, et al. (1995) Effects of aerobic exercise and dietary carbohydrate on energy-expenditure and body-composition during weight-reduction in obese rate. Am J Clin Nutr; 61 (3): 486-94

Rutherford, A., (2011), ANOVA and ANCOVA: A GLM Approach, 2nd Edition. Willey Inc., ISBN: 978-0-47038555-5

Sykes K, Choo LL, Cotterrell M. (2004) Accumulating aerobic exercise for effective weight control. $J R$ Soc Health; 24-8

van Aggel-Leijssen DP, Saris WH, Wagenmakers AJ, et al. (2001) The effect of low-intensity exercise training on fat metabolism of obese women. Obes Res; 9 (2): 86-96

Walberg JL. (1989) Aerobic exercise and resistance weight-training during weight-reduction: implications for obese and athletes. Sports Med; 7 (6): 343-56

Wilmore JH, Despres JP, Stanforth PR, et al. (1999) Alterations in body weight and composition consequent to 20 wk of endurance training: the HERITAGE Family Study. Am J Clin Nutr; 70 (3): 346-5

Zatsiorski, V. (1995), Science and practice of strength training. New York, Human kinetics.

http://epp.eurostat.ec.europa.eu/statistics explained/ index.php/Overweight and obesity - BMI statistics (accessed Jan 2015)

http://science.jrank.org/pages/321/Anaerobic-Anaerobic- respiration.html">Anaerobic - Anaerobic Respiration $</ a>$ (accessed May 2014)

http://www.psykiatri-regionh.dk/NR/rdonlyres/ B35B097D-5BF9-483B-B039-DA6953132177/0/ WHO5 Bulgarian.pdf (accessed June 2017)

http://www.winsteps.com/winman/bonferroni.htm (accessed Sep 2017) 